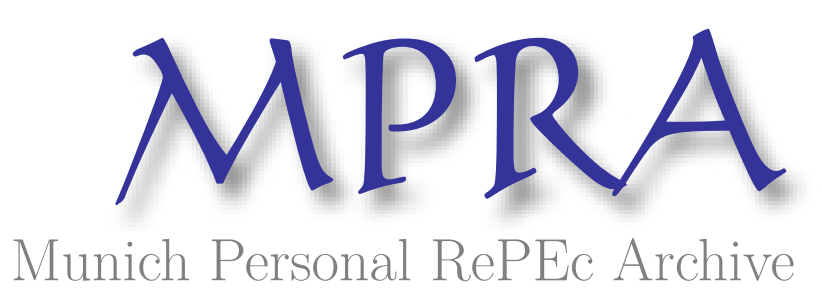

\title{
Regional Business Climate and Interstate Manufacturing Relocation Decisions
}

Conroy, Tessa and Deller, Steven and Tsvetkova, Alexandra

16 September 2015

Online at https://mpra.ub.uni-muenchen.de/66748/

MPRA Paper No. 66748, posted 17 Sep 2015 18:38 UTC 


\title{
Regional Business Climate and Interstate Manufacturing Relocation Decisions
}

\author{
Tessa Conroy \\ Department of Agricultural and Applied Economics \\ 521 Taylor Hall - 427 Lorch St \\ University of Wisconsin-Madison/Extension \\ Madison, WI 53706 \\ tessa.conroy@wisc.edu \\ Steven Deller \\ Department of Agricultural and Applied Economics \\ 515 Taylor Hall - 427 Lorch St \\ University of Wisconsin-Madison/Extension \\ Madison, WI 53706 \\ scdeller@wisc.edu \\ Alexandra Tsvetkova \\ Department of Agricultural Environmental Development Economics \\ 103 Agricultural Administration Building \\ 2120 Fyffe Road, \\ Ohio State University \\ Columbus, $\mathrm{OH} 43210$
}

Key words: business climate, manufacturing, firm relocation

JEL: R30, R31, O25, L60

An earlier version of this study was presented at the $46^{\text {th }}$ Annual Conference of the MidContinent Regional Science Association, May 2015. St. Louis, Missouri. All errors are the responsibility of the authors. Support for this work was provided by the Wisconsin Agricultural Experiment Station, University of Wisconsin - Madison and the University of Wisconsin Extension. 


\title{
Regional Business Climate and Interstate Manufacturing Relocation Decisions
}

\begin{abstract}
$\underline{\text { Abstract }}$
Using a panel (2000-2011) of cross-state relocation patterns of manufacturing firms from the National Establishment Time Series (NETS) database we estimate a state-to-state relocation model for all manufacturers and separately for three groups of industries defined by knowledge intensity. The analysis of the data suggests that very few manufacturing firms relocate across state lines in any given year and the vast majority of those that do are small in size and move to adjoining states. Econometric results reveal that regional determinants of relocation decisions vary by type of manufacturing firm. Whereas a number of factors considered in this study are significant in the models, estimated marginal effects at the mean are infinitesimal. This implies that states attempting to encourage manufacturing firms to relocate from other states via traditional perspectives on business climate are unlikely to be successful.
\end{abstract}

\section{INTRODUCTION}


Encouraging manufacturing firms to relocate from one state to another remains a popular economic development policy at both the state and local levels. To facilitate industrial recruitment state and local governments pursue a "positive business climate" through fiscal austerity, tax cuts, and other "pro-business" policies such as right-to-work legislation. Within this policy context the academic literature, both theoretical and empirical, seeks to better understand if such policies are effective. This literature remains vibrant for two reasons: (1) the policy is popular amongst elected officials and (2) as our data and research methods advance, the empirical results and corresponding policy insights become more subtle and refined.

From a policy perspective the contemporary "war between the states" tracks its origins to the Mississippi Balance Agriculture with Industry (BAWI) Act of 1933. Building on contemporary export base theory and neoclassical firm location theory, Mississippi attracted northern manufacturers by promoting cheaper labor and land, lower taxes, and limited regulations. The BAWI set the tone for how we think about business climate. Since then states actively engage in economic development policies that attempt to create an attractive business climate defined by low taxes, cheap labor, and minimal regulations (Deller \& Goetz, 2009; Eisinger, 1988; Ross \& Friedman, 1990; Shaffer, Deller, \& Marcouiller, 2004).

While the conventional approach to the business climate is multi-faceted, taxes and public services are perhaps the most widely studied within the academic literature. The early contributions based on work by Due (1961) and Oakland (1978) concluded that taxes had no impact on firm location decision because taxes were inconsequential in the accounting of profits. Since Wasylenko's $(1980,1981)$ challenge of those earlier conclusions for a lack of theoretical and empirical rigor, a new line of research has shifted the consensus. In a detailed review of the expansive literature, Bartik $(1985,1991,1992)$ concluded that taxes and other factors commonly 
associated with business climate do matter. Bartik's work and that which followed indicate that taxes are a cost to companies and a detriment to the business climate, but at the same time, taxes fund services, such as education, protective services, and transportation infrastructure, that are vital to the production processes of firms and increasingly to the quality of life of the firms' employees.

Regional and local economic development policies designed to attract and retain businesses often target specific industries and sectors. High-technology industries and those characterized by intensive research and development (R\&D) activities are a common focus for location incentives. In addition to promoting innovation and regional competitive advantage, such industries provide high-paying jobs and contribute to regional growth (Clarke \& Gaile, 1989; Jenkins, Jaynes, \& Leicht, 2006). If manufacturing firms are perceptive to business climate, it is important to understand which components of the business climate different types of firms prioritize. Within the product life cycle theoretical framework (Duranton \& Puga, 2001; Hong, 2014; Mack \& Schaeffer, 1993; Rink \& Swan, 1979; Wojan \& Pulver, 1995), industrial “maturity” determines companies' preferences. Businesses in more mature industries, or industries less likely to invest in innovation, are likely to seek out lower cost alternatives while newer and more innovation-focused industries may place higher value on other factors. Hence, the effectiveness of business attraction policies critically depends on the understanding of how relocation determinants vary across industries.

It is important to separate the study of factors that help understand relocation decisions from the study of the more general location decisions. As noted by Holl (2004), Hong (2014), Kronenberg (2013) and Manjón-Antolín \& Arauzo-Carod (2011), many previous studies treat relocation, new firm formation, and new branch location decisions equally in broad 
investigations of location choices, thus leading to potentially incorrect policy infrerences. In this study we focus on the factors behind interstate relocation decisions in the U.S. manufacturing between 2000 and 2011. By narrowing the analysis to existing manufacturing firms that relocate from one state to another we can explicitly compare and contrast the characteristics of the two states. This provides a more powerful test of the traditional business climate hypothesis compared to the previous location studies that explore whether or not a particular type of firm is within a region.

Using data from the National Establishment Times Series (NETS) database, we track individual firm moves across state lines annually in order to formalize and estimate differencesbetween-states models ${ }^{1}$. The models take into account important regional characteristics, such as agglomeration economies or tax and unionization rates, of both the origin and destination state for each move. This approach captures state-to-state flows, and unlike studies that look at aggregate in- or out-migration, allows for a better understanding of migration behavior. To the best of our knowledge, we are the first to use differences-between-states technique in a study of business migration. In addition to the analysis of all manufacturing firms, we separately investigate how relocation incentives measured by tax rates and service expenditures may vary with the level of research and development intensity within various industries.

Beyond these simple introductory comments the study is composed of four additional sections. In the next section we briefly review relevant theoretical and empirical literature explicitly focusing on relocations. In section three we outline the theoretical modeling framework followed by the empirical model and estimation methods in section four. In section five we outline the empirical results. We close with a summary of our findings and a discussion of their policy implications with a focus on broader manufacturing relocation patterns. 


\section{LITERATURE REVIEW}

A thorough review of the firm location literature is beyond the scope of this analysis; instead we limit the discussion to the theoretical and empirical aspects of firm relocations. The research to date has mostly been concerned with business location determinants, whereas literature that investigates relocation drivers is underdeveloped. Only recently, with availability of new data, researchers were able to analyze the patterns and determinants of firm migration.

The discussion of business relocation behavior is usually framed within three theories: neo-classical, behavioral, and institutional frameworks (Pellenbarg, Wissen, \& Dijk, 2002). Profit-maximization is the cornerstone of the neo-classical approach, which is the most widely adopted theoretical framework. Within this view all firms are assumed to be rational decision makers with full information, and perfect ability to process information about performance prospects in each potential location. By monitoring differences between expected revenues and expected costs across space relative to the current site a company decides to move if doing so maximizes profits. For manufacturing the "low-cost of doing business" is often more important for profit maximization than revenue streams.

The neo-classical perspective applies particularly well to large companies, which are likely to adopt more sophisticated algorithms of new site selection (Greenhalgh, 2008) and to move long distances to escape locational mismatch (Kalnins \& Chung, 2004), or exploit an opportunity (Stam, 2007). Empirically, studies of neo-classical relocation determinants focus on labor and transportation costs, market size, agglomeration economies and other, mostly regional, characteristics. The evidence suggests that companies are attracted by agglomerations (Erickson 
\& Wasylenko, 1980; Figueiredo, Guimarães, \& Woodward, 2002; Giuliano, 1989; Strauss-Kahn \& Vives, 2009), labor force availability (Erickson \& Wasylenko, 1980; Giuliano, 1989; Schmitt, Gleason, Pigozzi, \& Marcus, 1987), and access to transportation networks (Holguin-Veras et al., 2005; Ozmen-Ertekin, Ozbay, \& Holguin-Veras, 2007).

The institutional approach to business relocations contends that the existing institutions, such as governments, real estate brokerage industries, and regional economic development organizations among others, play an important role in determining whether a firm decides to change its location and what region it will select. Like the neo-classical theory, the institutional approach is more applicable to large companies, those possessing negotiating power, because a decision to move is viewed as a result of negotiations with community, suppliers and other economic and social actors (Brouwer, Mariotti, \& van Ommeren, 2004). At the same time, factors prominent within the institutional framework such as local policies and regulations, unionization rates, cultural norms (business-friendly cultural climate) and other regional characteristics are important for migration behavior of all firms regardless of their size. Although the empirical evidence is rather cursory, there are few rigorous studies that look at the effects of business relocation determinants within the institutional approach (Guimaraes, Rolfe, \& Woodward, 1998; Lee, 2008; Oukarfi \& Baslé, 2009)².

The behavioral perspective on business relocations focuses predominantly on the firm itself. Within this framework, a company is an actor with bounded rationality that does not possess all the information about business prospects in various locations and has limited ability to process that incomplete information. Firm's characteristics, internal processes, levels of risk aversion, and willingness to accept uncertainty play an important role. The theory is particularly suited to study the relocation behavior of small firms, as well as short-distance moves. It can also 
explain why relocation is such a rare phenomenon dominated by short-distance moves (van Dijk \& Pellenbarg, 2000) $)^{3}$.

In general, objective and subjective relocation costs increase with distance. These costs include those associated with uncertainty and the potential loss of employees, in addition to actual expenses of physical change of place. Research shows that risk and uncertainty decrease the likelihood of relocation (Pennings \& Sleuwaegen, 2000). Companies considering a change of site, especially those investing heavily in their labor force, are less likely to move because employees may not change their residence in order to keep the job (Carter, 1999; Lawson \& Angle, 1998; Otto \& Dalbert, 2010). Like employees, companies are often 'embedded' in their locations for personal reasons, such as existing networks (Knoben \& Oerlemans, 2008), or attachment of the owners or managers to a particular place (Halstead \& Deller, 1997). This is especially true for smaller companies whose decision process is more likely to be dominated by one person (Greenhalgh, 2008). The value of staying in the home community is so high that in some circumstances entrepreneurs may be willing to face much higher costs of doing business (Figueiredo et al., 2002).

With respect to firm characteristics, size and age on average hamper proclivity to move (Brouwer et al., 2004; Knoben \& Oerlemans, 2008; Nguyen, Sano, Tran, \& Doan, 2013; van Dijk \& Pellenbarg, 2000), although this does not apply to international business migration and migration of headquarters (Pennings \& Sleuwaegen, 2000; Strauss-Kahn \& Vives, 2009). At the same time, expansion is one of the major triggers of (short-distance) relocations (Brouwer et al., 2004; Knoben \& Oerlemans, 2008; van Dijk \& Pellenbarg, 2000). Firms may simply outgrow their existing facility and relocate to larger premises often within the same community. 
This study draws insight from all three relocation frameworks described above. It focuses on interstate migration flows, which are considered long-distance moves. Such relocations are usually triggered by regional factors (Weterings \& Knoben, 2013). The neo-classical and institutional perspectives therefore, provide the foundation for this study but with influence from the behavioral approach. Empirically, our estimation strategy takes into account regional characteristics of both the origin and destination states. We use the differential between the origin and destination on several key variables to more precisely measure the incentives to relocate. We analyze the full set of manufacturing relocations as well as three subsets distinguished by their knowledge intensity, which is inevitably linked to the non-uniform distribution of perceptions and abilities among companies well in line with the behavioral framework. The variability in perceptions and abilities (together with other factors) should shape business migration propensity and relocation patterns.

\section{THEORETICAL FRAMEWORK}

The research on business climate metrics and manufacturing migration seldom distinguishes between location and relocation determinants (Holl 2004; Kronenberg 2013; Manjón-Antolín \& Arauzo-Carod 2011). Location decisions include both relocation and new start-up decisions. Analysis of manufacturers by Conroy and Deller (2014), Halstead and Deller (1997) and Pellenbarg, Wissen and Dijk (2002) finds that most manufacturers stay in their original location because the owner is not inclined to change the place of his or her residence. Indeed, most manufacturing firms never relocate. Thus, studies that blend the relocation 
decision made by incumbents with the startup location decisions by new companies are ignoring potentially important differences in the two types of decisions.

A more precise understanding of the factors that motivate relocation requires modeling the movement of established firms from one location to another. We implement a state-to-state migration modeling approach in this study. Its advantage is the ability to directly compare the characteristics of the origin and destination states and to draw inferences based on the differential. Although such a 'differences' modeling technique has been used in population migration studies recently (Ali, Partridge, \& Rickman, 2012; Betz \& Partridge, 2013), to the best of our knowledge, we are the first to apply this approach to the study of business relocations.

Building on neo-classical theory, the firm location literature often focuses on cost minimization policies implying that those locations that maximize profits via the lowest cost are most attractive and correspond to a high rate or count of in-migration. We argue, however, that relocation incentives are more precisely measured with a differences approach. If conventional recruitment strategies are correct, the propensity for a firm to move should increase with the tax rate differential between the origin and destination states. Thus, we expect that low tax states are attractive to manufacturers only to the extent that taxes in the destination state are lower than the taxes in the firm's origin state. This intuition implies that, all else equal, firms in high-tax states have greater incentive to move to the lowest-tax state than do firms already in a state with moderately low taxes. Thus, the differences approach allows for a more precise specification because it better measures the incentives for moving. Further, the empirical model based on differences approach allows us to include both taxes and expenditures without concern for collinearity. 
Consider a profit maximizing manufacturing firm $i$ that is currently at location $k$ and is considering relocation over a range of regions (states) $k=1, \ldots, K^{4}$. The firm faces prices for inputs $w_{i}^{k}$, the firm's output $p_{i}^{k}$, a level of taxes $t_{i}^{k}$ and corresponding level of public services $G_{i}^{k}$ all at the current location $k$. Its profit function can be expressed as:

$$
\pi_{i}^{k}\left(w_{i}^{k}, p_{i}^{k}, t_{i}^{k}, G_{i}^{k}\right)
$$

In a potential destination region (state) $k^{D}$ this firm faces an alternative profit:

$$
\pi_{i}^{k^{D}}\left(w_{i}^{k^{D}}, p_{i}^{k^{D}}, t_{i}^{k^{D}}, G_{i}^{k^{D}}\right)
$$

The firm will decide to relocate if the expected profits of moving to a new location (state), expressed as $E\left(\pi_{i}^{k^{D}}\right)$ exceeds the expected profit from remaining at its current location, $E\left(\pi_{i}^{k}\right)$. To simplify assume that market for the manufacturing firm's product is not affected by the firm's ultimate location, or $p_{i}^{k^{D}}=p_{i}^{k}$. The expected profit functions at the two locations can be expressed as:

$$
E\left(\pi_{i}^{k}\right)=-\beta^{k} w_{i}^{k}-\alpha^{k} t_{i}^{k}+\gamma^{k} G_{i}^{k}+\epsilon_{i}^{k}
$$

and

$$
E\left(\pi_{i}^{k^{D}}\right)=-\beta^{k^{D}} w_{i}^{k^{D}}-\alpha^{k^{D}} t_{i}^{k^{D}}+\gamma^{k^{D}} G_{i}^{k^{D}}+\epsilon_{i}^{k^{D}}
$$

where $\epsilon_{i}^{k}, \epsilon_{i}^{k^{D}} \sim N\left(0, \sigma^{2}\right)$ and $\beta^{k}, \beta^{k^{D}}, \alpha^{k}, \alpha^{k^{D}}, \gamma^{k}, \gamma^{k^{D}}>0$.

The firm will elect to move if:

$$
M^{k, k^{D}}=E\left(\pi_{i}^{k^{D}}\right)-E\left(\pi_{i}^{k}\right)>0
$$


To further simplify the formal presentation of the theoretical framework assume that the parameters of the expected profit functions are the same across firms and locations, or $\beta^{k}=\beta^{k^{D}}$, $\alpha^{k}=\alpha^{k^{D}}$ and $\gamma^{k}=\gamma^{k^{D}}$. This allows us to rewrite the decision rule to stay at the current location or to move as:

$$
M^{k, k^{D}}=-\beta^{*}\left(w^{k^{D}}-w^{k}\right)-\alpha^{*}\left(t^{k^{D}}-t^{k}\right)+\gamma^{*}\left(G^{k^{D}}-G^{k}\right)+\epsilon
$$

where $\epsilon=\epsilon^{k^{D}}-\epsilon^{k}$. In the simplest sense the firm is comparing and contrasting the costs $(\omega, t)$ of the two locations along with the benefits of the public services being offered $(G)$.

Given the neo-classical foundation adapted, this framework provides a theoretical justification for promoting low costs of operations, as firms will prefer low cost alternatives for a given level of public services. Indeed, within this framework the insights from behavioral and institutional theories of firm location can be tapped to help explain the observed dynamics of business moves (Brouwer et al., 2004; Nguyen et al., 2013; Pellenbarg et al., 2002). For example, firm characteristics, such as age, market power, knowledge intensity and others determine its ability to benefit from the environment via local knowledge spillovers. Such ability, in turn, is often related to greater productivity and innovation (Ibrahim, Fallah, \& Reilly, 2009; Koo, 2005; Zachariadis, 2003), which are likely to contribute to cost reduction.

The ability to gather and process information about all potential locations and willingness to assume risk and accept certain levels of uncertainty further complicates the decision rule outline above. Rather than assuming that the parameters of the expected profit functions are the same across all locations $\left(\beta^{k}=\beta^{k^{D}}, \alpha^{k}=\alpha^{k^{D}}\right.$ and $\left.\gamma^{k}=\gamma^{k^{D}}\right)$ it is likely that firms will discount the values at potential location $k^{D}$. Given the institutional and behavioral theories it is 
more likely that $\beta^{k}>\beta^{k^{D}}, \alpha^{k}>\alpha^{k^{D}}$ and $\gamma^{k}>\gamma^{k^{D}}$ reducing the likelihood of a relocation. Intuitively, the variance around the expected profitability at a new location $E\left(\pi_{i}^{k^{D}}\right)$ is larger than where the firm is currently located $E\left(\pi_{i}^{k}\right)$ again reducing the likelihood of a relocation. This is particularly true for more risk adverse manufacturers and smaller firms that lack negotiating power. The derivation above does not include the costs of relocation. For many types of manufacturing moving equipment can be prohibitive further reducing the likelihood of relocation. In essence, manufacturing firms may not be as freely mobile as implied by the traditional neo-classical framework

\section{EMPIRICAL MODEL AND DATA}

The empirical representation can be expressed for our panel of data as:

$$
M_{i j, t}=\sum_{l=1}^{n} \theta_{l} \Delta x_{l, i j t}+N_{i, j}+T_{t}+\varepsilon
$$

where $\Delta x_{l, i j}$ a is the difference between state $i$ and state $j$ across a set of $l$ empirical variables in year $t, N$ is a dummy variable that equals to one if two states are neighbors, and $T$ is a time fixed effect. We model relocation $\left(M_{i j, t}\right)$ as the actual flow or movement from state $i$ to state $j$. Because of the count nature of our data, a Poisson or negative binomial estimator is most appropriate. To allow for the presence of unobserved heterogeneity we elect to use the negative binomial estimator ${ }^{5}$. By design the distribution of the dependent variable $\left(M_{i j, t}\right)$ is truncated at zero. Specifically, we are modeling incidents of positive movement between any two states and thus only positive integers are within the space of the dependent variable. 
As demonstrated in Figure 1, there are 8,750 origin-destination state pairs with positive relocation counts over the study period. There is just one firm moving between most origin destination state pairs in any given year accounting for 51.1 percent of the observations. For example, in 2010 one manufacturer relocated from Alabama to Arizona. The second most common scenario of two relocations between any two states accounts for 19.8 percent of the observations. The largest relocation count is 62 firms that moved from New York to New Jersey in 2009. Overall, movement from New York to New Jersey accounts for the five largest relocation flows with 49 firms in 2004; 51 in 2001; 52 in both 2000 and 2003. But it is important to note that the relocation flows move in both directions. While the largest relocation flows are from New York to New Jersey, there are also manufacturers moving from New Jersey to New York: 32 in 2011, 31 in 2004, 30 in both 2008 and 2009 and 29 in 2003.

Given the distribution of relocations described in Figure 1 we use a truncated negative binomial estimator:

$$
\operatorname{Pr}(Y=y \mid y>0, \mu, \alpha)=\frac{\operatorname{Pr}(\mathrm{Y}=\mathrm{y} \mid \mu)}{1-\operatorname{Pr}(Y=0 \mid \mu)}
$$

where $\operatorname{Pr}(Y=0 \mid \mu, \alpha)=(1+\alpha \mu)^{-\alpha^{-1}}$ and the conditional expected value of $y$ is given by $\mathrm{E}(y \mid y>0, \mu, \alpha)=E(y \mid \alpha \mu) /[1-\operatorname{Pro}(y=0 \mid \mu, \alpha)] . \mu$ is the negative binomial parameter to be estimated and $\alpha>0$ is a dispersion parameter. As $\alpha \rightarrow 0$ the negative binomial model converges to the Poisson model. A property of the negative binomial is that the conditional variance $V(y \mid \mu)=\alpha+\alpha \mu^{2}$ exceeds conditional mean $E(y \mid \mu)=\mu$.

The model is estimated via maximum likelihood and the log-likelihood function is given by: 


$$
\begin{gathered}
\left.\ell(\beta, \alpha)=\sum_{i=1}^{n}\left(\sum_{j=0}^{y} \ln \left(j+\alpha^{-1}\right)-\ln y_{i} !-\left(y_{i}+\alpha^{-1}\right) \ln \right) 1+\alpha \mu\right)+ \\
\left.y_{i} \ln \alpha \mu-\ln \left[1-(1+\alpha \mu)^{-\alpha^{-1}}\right]\right)
\end{gathered}
$$

where $\left(\Sigma_{j=0}^{y} \ln \left(j+\alpha^{-1}\right)=\ln \Gamma\left(\left(j+\alpha^{-1}\right)-\ln \Gamma\left(\alpha^{-1}\right)\right.\right.$ if $y_{i}$ is an integer and $\Gamma(\cdot)$ is a gamma function.

Treating manufacturing as one industry in any study of relocation determinants may lead to aggregation bias. We know from a theoretical perspective that, for example, within the product life cycle framework (Duranton \& Puga, 2001; Hong, 2014; Mack \& Schaeffer, 1993; Rink \& Swan, 1979; Wojan \& Pulver, 1995), firms at different levels of "maturity" view business climate through very different lenses. More mature industries look for lower cost alternatives while newer industries may place higher value on other factors. Duranton and Puga (2001) report that relocation patterns are identifiable along the $R \& D$ continuum in an examination of French manufacturers. As long as the level of innovation within an industry is related to its maturity, this finding is well in line with the product life cycle hypothesis. Thus, for this study we divide all manufacturing industries into three groups based on their spending on research and development. We then look at the relocation decisions of all manufacturers as a whole and across three classifications: low, medium, and high R\&D intensity.

Our empirical specification includes several variable categories: (1) size and agglomeration metrics, (2) labor characteristics, (3) energy costs, (4) taxes, (5) government services, and (6) indicators of the state business and political environment. The existing research commonly confirms the importance of agglomeration economies for relocation decisions with concentrations of firms in one industry attracting other companies within same industry (Deller, 2009; Figueiredo et al., 2002; Schaffer, Deller, \& Marcouiller, 2004; Strauss-Kahn \& Vives, 
2009). To account for potential agglomeration effects the models estimated in this study include the share of state total employment in manufacturing. In line with expansive literature, we expect that states with more intensive manufacturing would attract manufacturing firms from regions that are characterized by lower concentration of this sector (e.g. Asheim, Cooke, \& Martin, 2006; Pitelis \& Pseiridis, 2006; Shields, Barkley, \& Emery, 2009; Sugden, Wei, \& Wilson, 2006; Woodward \& Guimarães, 2009). To capture the size of manufacturing sector in a state we include the state's share of US gross domestic product within manufacturing.

We include state-wide annual compensation within manufacturing in our specifications to control for labor costs faced by companies in the origin and destination states. After controlling for the effects of agglomeration, higher labor costs (compensation rates) are expected to deter manufacturers from relocating. Several studies find that labor unions generally deteriorate regional business climate (Bartik, 1985; Woodward \& Rolfe, 1993): higher rates of unionization are associated with lower in-migration of firms (Conroy, Deller, \& Tsvetkova, 2015; Lee, 2008). Still some studies, such as Bellace (2014), argue that declining membership in labor unions has undermined the relationship between unionization and manufacturing location patterns identified by prior research that needs to be revisited.

The availability of labor with relevant skills undoubtedly factors into the migration decision of firms (Ozmen-Ertekin et al., 2007). We include share of the adult population (age 25 and over) with at least a Bachelor's degree, but offer no universal hypothesis. In the context of manufacturing, the required skill levels of the workforce likely differ across industries. The manufacturing sector consists of the industries heavily reliant on the low-skill labor and industries that require highly trained and educated employees. Along the R\&D continuum the former are likely to spend very little on research and development, whereas the latter are likely to Page | 16 
be knowledge-intensive. We expect the effects of the education variables to vary across the models that focus on different levels of R\&D intensity. In low R\&D spending sectors, there may be little need for educated researchers and more generally skilled workers, thus an educated workforce would have little, if not a negative, effect. Firms in the sectors characterized by high R\&D intensity are more likely to rely on highly trained workers, thus an educated workforce would attract more knowledge-intensive firms. In addition to education, unemployment captures the level of economic hardships in a state but it also may signal availability of (cheap) labor. We expect this variable to play a role for relocations of less knowledge-intensive establishments.

Energy costs, particularly the cost of electricity, often are a sizable component of the operations costs in manufacturing and, hence, should be important consideration in relocation decisions (Carlton, 1983). In a policy context, some policy makers question alternative energy sources, such as wind and solar, because the associated higher costs may negatively impact the business climate. Though some studies find that energy costs are insignificant in the models of location (Bartik, 1985; McConnell \& Schwab, 1990), we include the state-wide average electricity rate as a measure of input costs that vary regionally.

Government taxation and service provision are crucial elements of regional business climate. High taxes, regardless of the services they fund, are usually unattractive to businesses. Though early reviews conclude that taxes have no impact on firm location decisions (see Due, 1961; Oakland, 1978), later analysis based on more rigorous theoretical and empirical modeling provides evidence that taxes matter for economic growth. Despite this fact, some commentators note that the effects of taxes "should be treated as an open rather than a settled question" (Newman \& Sullivan, 1988, p.232). We provide further investigation of the impacts of taxes in the context of manufacturing firm relocations. The models estimated in this study include three 
types of taxes: corporate income taxes, personal income taxes, and property taxes. To control for the size of the state economy, we adjust each type of revenue by total personal income.

Our modeling strategy allows for inclusion of both taxes and expenditures in the same specification. This feature of the model is valuable because just a few studies consider how tax revenues are used to fund public services, which may also impact business migration. Based on the current state of the literature one can conclude that taxes have a negative, although weak, effect on economic activity giving some credence to the notion that high taxes deteriorate business climate. Yet, taxes pay for public education, which is vital to the productivity of the workforce, and for the transportation infrastructure that is an important consideration in business relocation decisions (Holguin-Veras et al., 2005; Ozmen-Ertekin et al., 2007). We expect education expenditures to have a positive impact on migration as improvements in human capital can have utility to a variety of firms. Human capital investments, such as public education, onthe-job training, and health care among others, influence the economic growth process by increasing the productive capacity of the labor force by augmenting skills, knowledge, health, or other productive attributes (Beaulieu \& Mulkey, 1995; Clark, 1983; Goetz \& Hu, 1996; Hanushek \& Woessmann, 2015; Wilson \& Briscoe, 2004).

Public capital and public infrastructure in particular are crucial for a variety of economic outcomes (Aschauer, 1989a, 1989b, 1989c; Holtz-Eakin, 1992; Tatom, 1991a, 1991b). Like Bergh and Henrekson (2011), Bartik (1991, 1992) and Barro (1991), we take the view that public capital is broader than simple physical infrastructure and includes "productive" public amenities such as protective services and environmental protection. We assume that there is a balance between the potentially negative effects of taxation, which can hinder business climate, and the positive effects of productive public goods and services, which are intended to promote the 
business climate. Thus, in addition to our tax variables, we have three broad measures of what we suggest are productive public goods: expenditures on higher education, expenditures on K-12 education, and expenditures on highways and transportation. We include two non-productive expenditure categories: welfare, including public expenditures on health care, and corrections, including police, jails and prisons. As with the taxation variables, these measures are per $\$ 1,000$ of personal income.

Another set of variables focuses on the political environment in a state. As suggested by the institutional theory of business (re)locations, public institutions play an important role in the migration behavior of firms. Some research suggests that the Democratic Party may be perceived as less “business-friendly” (Grant, 1996; Klassen \& Shackelford, 1998) potentially deterring inmigrating companies. Democrats tend to favor higher funding for government services over lower taxes, a stronger regulatory environment and pro-labor policies. We expect manufacturers to be less likely to be drawn to majority-Democratic states. We include the percent of state legislative seats that are held by Democrats to capture the effects of party politics. Because political conflict can add uncertainty to business climate and uncertainty is costly to relocating firms (Pennings \& Sleuwaegen, 2000) we include the rate at which governors use their veto authority in the models. We expect businesses to be less likely to relocate to a state with higher levels of political conflict.

In addition to the variables described above our models include the Beacon Hill Competitiveness Index. State and local media along with economic development practitioners tend to draw attention to the rankings that appear to make a region look particularly attractive. Rankings, such as Money Magazine’s “Best Places to Live” or Forbes Magazine’s “Best States for Business" or the various rankings offered by Site Selection Magazine, are widely used as a 
form of boosterism in promotion of favorable business climate to outsiders. While these types of rankings are widely dismissed in the academic literature (e.g. Lane, Glennon, \& McCabe, 1989) we include the Beacon Hill Competitiveness Index for completeness. The advantage of the Beacon Hill Index is that it is available over the period of analysis for this study and is relatively consistent in methodology from one year to the next. We expect manufacturers to be attracted to states with higher values of the Index.

We also include a dummy variable to control for relocations between neighboring states. In a descriptive analysis of the NETS data focusing on Wisconsin, Conroy and Deller (2014) find that the vast majority of firms that relocate out of state move to an adjacent state. Often these moves are simply across the state line. Neumark et al. (2006) provide comparable evidence for the state of California. This makes intuitive sense within the behavioral approach to firm relocations: as a company moves farther from the current location, information costs become higher, as well as the variance of error in the expected profit function. For these reasons we expect a higher proportion of manufacturing firms to relocate to nearby states.

Finally, the factors that are considered in relocation decisions may differ across manufacturing firms. The product life cycle model (see Rink \& Swan, 1979) implies that as manufacturing becomes more mature and less focused on innovation it seeks out lower cost alternatives (Duranton \& Puga, 2001; Hong, 2014; Mack \& Schaeffer, 1993; Wojan \& Pulver, 1995). On the other hand, manufacturing companies in newer industries tend to be more focused on innovation and to benefit from Jacobian externalities associated with agglomeration economies. It follows that the knowledge-intensity of industries at different stages of product life cycle is likely to differ. Using R\&D spending data from the National Science Foundation (2014) we group manufacturing firms into three subsets depending on their industrial affiliation: 
low, medium and high. The firms in "low" R\&D spending group are deemed less innovative and less likely to benefit from agglomeration economies. Consequently, their relocation decisions are expected to be primarily motivated by cost differential. Firms within more innovation-focused industries are likely to be at a different point on the product life cycle continuum. Such companies ("medium" and "high" R\&D spending groups in our study) should be attracted by agglomeration economies. Our grouping of industries based on $R \& D$ spending is provided in Table $1^{6}$, whereas Table 2 contains descriptive statistics for the variables.

\section{EMPIRICAL RESULTS}

To discuss the results, we follow the structure implied by the grouping of our variables and draw comparisons across research and development intensity throughout. For interpretation of the results presented in Table 3, one needs to keep in mind that the variables are measured relative to the value in the origin state: $\Delta x_{l, i j t}=x_{i}-x_{j}$. This method implies that if the difference is positive, the variable takes on a higher value in the origin state $i$. The dependent variable is the count of firms moving from state $i$ to state $j$. So, a positive coefficient combined with a positive value of $\Delta x_{l, i j t}$ implies more firms moved out of state $i$ to state $j$. For example, if the coefficient on the tax rate is positive and significant and the tax rate in state $i$ is higher than in state $j$, then the results indicate that more firms are moving from the high-tax state $i$ to the lowtax state $j$. That is, a positive coefficient implies that low values of a variable (i.e. corporate taxes) are attractive to manufacturing firms and negative coefficients imply that a higher value of a variable (i.e. spending on higher education) is attractive. 
The size of the manufacturing sector plays a role in relocation decisions. Manufacturers tend to exit states with a high share of U.S. manufacturing GDP and go to those with a relatively low share. This result holds in the pooled model of all migration, but seems to be driven primarily by medium and high research and development type companies. There is no significant effect among firms in industries with low research and development intensity. The observed results could be driven by the single state of California, which is the largest manufacturer in the country, but usually loses firms to other states (Neumark et al., 2006). In terms of agglomeration effects, the share of state employment in manufacturing is weakly significant among high R\&D manufacturers. The coefficient is negative suggesting migration is higher from states with a low share of employment in manufacturing to states with a relatively large share of employment in manufacturing. This result is consistent with the product life cycle model and the prior findings within manufacturing context (Duranton \& Puga, 2001; Hong, 2014; Mack \& Schaeffer, 1993; Wojan \& Pulver, 1995). It appears that more innovative firms, as evidenced by spending on research and development, benefit more from the Jacobian externalities associated with agglomeration economies. The benefits of Jacobian externalities to less innovative firms perhaps are not sizable enough to outweigh potentially higher costs associated with agglomerated spatial markets.

Estimation results suggest that the only labor consideration relevant to manufacturing migration is the rate of union membership. Neither the unemployment rate, nor the share of population with at least a bachelor's degree have any effect on manufacturers' relocation decision, regardless of their research and development intensity. Union membership, however, has a strong positive effect on migration flows across low, medium, and high research and 
development groups, suggesting that firms leave highly unionized states in favor of those with lower union membership, a result that is consistent with the traditional view of business climate.

Energy costs have only a weakly positive effect on relocation. In the regression pooling all firms and in that for high R\&D firms, the coefficient is positive but only weakly significant, suggesting that firms leave states with relatively high energy costs for destination states with lower electricity rates. Again, this result is consistent, although weakly from a statistical perspective, with the traditional view of business climate.

The impact of taxes on manufacturing relocation varies both by the type of tax and the R\&D intensity of the firms but seems to have the most influence on companies in knowledgeintensive industries. First, corporate income taxes have positive and significant effect on the migration of high R\&D firms only. Thus, at the highest levels of R\&D spending, firms tend to leave states with high corporate income tax rates for destinations that have lower rates. In contrast, property taxes have a negative effect on migration among high $R \& D$ manufacturing firms. The negative and significant coefficient indicates that firms tend to exit states with relatively low property taxes in favor of those with higher property taxes. This may signal the importance of the amenities funded by property taxes to the owners and managers of firms in knowledge-intensive industries. Last, income taxes have a positive and significant effect on the migration of low R\&D firms and all firms pooled together. As expected, the results indicate that firms leave states with relatively high individual income taxes.

In general, spending on government services influences primarily low and medium R\&D manufacturing firms. None of the expenditures influence the subset of high R\&D firms. Spending on higher education does seem to attract firms, but it appears that relationship is driven primarily by migration among low R\&D firms. The negative and strongly significant 
coefficient indicates that low $R \& D$ firms tend to flow from states with low spending on higher education to those that spend relatively more. Spending on K-12 education tends to correspond to more migration from states that spend more to those that spend less, but this result holds only for the subset of medium R\&D manufacturing firms. The negative and strongly significant coefficient in the pooled model on welfare programs implies migration from states with low welfare spending to states with high welfare spending. While this is true for all firms generally, this result is not especially strong in any subset of manufacturers. Lastly, relatively low spending on highways and roads seems to be at least weakly attractive to low R\&D manufacturers.

Together, the last group of variables gives a sense of the state business and political environment. First, despite its popularity as a recruitment device, the Beacon Hill Competitiveness Index appears to have no influence on manufacturing migration. This is consistent with other studies that find that rankings like this provide little insight into actual firm location decisions (Lane et al., 1989). Similarly, despite the pro-business identity of the Republican Party, and opposing image of the Democratic Party, the majority party of the state legislature has no influence on manufacturing migration. The rate of gubernatorial veto is also without influence.

Overwhelmingly, manufacturing firms move to neighboring states. This result is not surprising as information asymmetries increase with distance, thus short-distance moves are likely to be better informed and perceived as less uncertain. This makes such moves an attractive option compared with long-distance moves. In fact, the majority of our variables that characterize various aspects of the business climate have remarkably smaller impact on migration than does the simple coincidence of neighboring locations. 
The coefficient estimates provided in Table 3 alone do not convey the magnitude of the economic effects of the explanatory variables on the count of firms that migrate between any two states. Marginal effects give a better sense of how a change in any one of our policy variables would influence relocation decisions on average. For each specification the marginal effects at the mean are reported in Table 4. Despite the statistical significance of several variables in each model, the marginal effects indicate that their economic significance is small if not trivial. The marginal effects of the policy variables are several orders of magnitude larger for high R\&D manufacturers, but still quite small in terms of economic importance. For instance, the marginal effects of taxes imply that in order to increase the expected number of relocating firms by one states would need to implement massive tax cuts.

As previously discussed, a very small share (1-5\% depending on the source) of manufacturers move each year. On average in our sample, fewer than three firms move between any two states per year. The rarity of manufacturing relocations may partly explain the extremely small marginal effects. More importantly, however, the small marginal effects combined with the infrequency of relocations have important policy implications. While it is the case that unionization, taxes, and some public spending have a statistical relationship to manufacturing interstate migration, the impact of any feasible policy change related to any business climate components considered in this study is likely to be negligible.

\section{CONCLUSIONS AND DISCUSSION}

With this study we contribute to the still underdeveloped literature that investigates business relocation determinants. Our focus on firm relocations, as opposed to the more general 
question of firm location decisions, is motivated by the prevalence of state policies that try to attract companies from elsewhere coupled with very limited evidence on the effectiveness of such incentives. We focus on the manufacturing firms that changed the state of their location during the 2000-2011 time period as indicated in the NETS database. To better capture the nature of the firm relocation decisions, we use a differencing modeling approach, which simultaneously takes into account multiple characteristics of both origin and destination states, and examines the importance of these regional traits for all manufacturing firms, as well as separately for three subsets of industries defined by the level of research and development (R\&D) spending.

Given the preferential treatment often offered by states and localities to companies in knowledge-intensive sectors, the results of our study are particularly relevant to the discussion of attraction packages and business climate in general. We find that divergent sets of determinants shape relocation decisions within the studied groups. On average, manufacturers that tend to be more innovative, as proxied by spending on $\mathrm{R} \& \mathrm{D}$, appear to be more likely to take into account regional characteristics, which may be welcome news for policy-makers. Such companies tend to leave states with larger share of U.S. manufacturing output in favor of states with lower share but prefer to relocate to the states whose employment is more concentrated in manufacturing. They are somewhat responsive to energy costs, avoid states with higher union membership rates and prefer to move out of states with higher corporate income taxes but are attracted to the states that levy more on property. This may point to the importance of amenities funded by property taxes to the firms in knowledge-intensive industries, although wider spending categories considered in this study do not influence their relocation choices. These results are rather expected if one takes into account the ability of such companies to draw labor from across the nation and relative unimportance of transportation infrastructure in their production process. 
On the other side of the spectrum, manufacturing establishments in the industries characterized by the low intensity of spending on $R \& D$ prefer to relocate to the states with lower unionization rates and lower personal income taxes. Companies in the sectors with low knowledge intensity appear to be the most sensitive to what we refer to as productive public capital. They are drawn to the states that spend more on higher education and transportation infrastructure.

While we find some statistical evidence supporting relevance of the traditional notions of a positive business climate in manufacturing relocation decisions such as low costs of operations, the negligible marginal effects of the variables call into question the economic significance of the relationships between considered regional characteristics and relocation choices. On face value, many of our findings are consistent with Bartik's $(1985,1991,1992)$ conclusion that taxes and other factors generally associated with business climate play a role in business location decisions. The magnitude of the marginal effects, however, is so small that earlier views of the tax policy ineffectiveness in determining location behavior of firms (Due, 1961; Oakland, 1978) seem to be closer to reality. Thus "low road" approaches to promoting a positive business climate with the purpose of attracting companies from other states are not likely to be effective. 
${ }^{1}$ The National Establishment Time Series (NETS) is a database of U.S. establishments developed and annually updated by Dun \& Bradstreet (D\&B) in partnership with Walls \& Associates. The NETS database is uniquely detailed providing location information for each establishment, which is an important advantage over other available data sources. The data include the location of each establishment at its start, as well as the year and address of any relocation during the life of a business making it possible to track relocation decisions and migration patterns. Neumark, Zhang, and Wall (2006) find that the information on interstate relocations of establishments contained in the NETS is particularly reliable.

${ }^{2}$ This lack of a well-established rigorous empirical literature could be due to the difficulty to directly quantify many factors that are most relevant to the institutional perspective.

${ }^{3}$ This statement is applicable to headquarters to a lesser extent. Whereas relocation is a rare event for the majority of firms, headquarters appear to be more likely to move. Besides, the determinants of headquarter relocations seem to be different from other types of establishments (Strauss-Kahn \& Vives, 2009).

${ }^{4}$ This derivation follows Grassmueck, Goetz, and Shields (2008).

${ }^{5}$ We used both estimators and found little differences in the final results. Thus for brevity we report only the more general negative binomial results.

${ }^{6}$ This grouping is consistent with the model developed by Duranton and Puga (2001). 


\section{References}

Ali, K., Partridge, M., \& Rickman, D. (2012). International immigration and domestic out-migrants: are domestic migrants moving to new jobs or away from immigrants? The Annals of Regional Science, 49(2), 397-415. doi: 10.1007/s00168-011-0456-2

Aschauer, D. (1989a). Does public capital crowd out private capital? Journal of Monetary Economics, 24(2), 171-188.

Aschauer, D. (1989b). Is public expenditure productive? Journal of Monetary Economics, 23(2), 177-200.

Aschauer, D. (1989c). Public investment and productivity growth in the Group of Seven. Economic Perspectives, 13(5), 17-25.

Asheim, B., Cooke, P., \& Martin, R. (2006). The rise of the cluster concept in regional analysis and policy. Clusters and regional development: critical reflections and explorations, 1-29.

Barro, R. J. (1991). Economic growth in a cross section of countries. The Quarterly Journal of Economics, 106(2), 407-443.

Bartik, T. J. (1985). Business location decisions in the United States: Estimates of the effects of unionization, taxes, and other characteristics of states. Journal of Business \& Economic Statistics, $3(1), 14-22$.

Bartik, T. J. (1991). Who benefits from state and local economic development policies? Books from Upjohn Press.

Bartik, T. J. (1992). The effects of state and local taxes on economic development: A review of recent research. Economic Development Quarterly, 6(1), 102-111.

Beaulieu, L. J., \& Mulkey, D. (1995). Human capital in rural America: A review of theoretical perspectives. Investing in people: The human capital needs of rural America, 3-21.

Bellace, J. (2014). American unions and the economy - the unheard voice of a shrinking sector. The Singapore Economic Review, 59(04), 1450029.

Bergh, A., \& Henrekson, M. (2011). Government size and growth: a survey and interpretation of the evidence. Journal of Economic Surveys, 25(5), 872-897.

Betz, M. R., \& Partridge, M. D. (2013). Country road take me home: Migration patterns in Appalachian America and place-based policy. International Regional Science Review, 36(3), 267-295.

Brouwer, A. E., Mariotti, I., \& van Ommeren, J. (2004). The firm relocation decision: An empirical investigation. The Annals of Regional Science, 38, 335-347.

Carlton, D. W. (1983). The location and employment choices of new firms: An econometric model with discrete and continuous endogenous variables. The Review of Economics and Statistics, 440-449.

Carter, S. (1999). Relocation or dislocation? Key issues in the specialist management of group moves. Management Research News, 22(5), 22-36.

Clark, G. L. (1983). Fluctuations and rigidities in local labor markets. Part 1: theory and evidence. Environment and Planning A, 15(2), 165-185.

Clarke, S., \& Gaile, G. (1989). Moving towards entrepreneurial local development strategies: Opportunities and barriers. Policy Studies Journal, 17(3), 574-598.

Conroy, T., \& Deller, S. (2014). Wisconsin establishment migration: 2000-2011 Patterns of Economic Growth and Development Study Series No.1. Madison, WI: University of Wisconsin-Madison.

Conroy, T., Deller, S., \& Tsvetkova, A. (2015). Factors affecting the interstate migration of manufacturing firms: Much ado about nothing? Staff paper No.578. Madison, WI: University of Wisconsin-Madison.

Deller, S. (2009). Overview of firm location theory and TRED. In S. Goetz, S. Deller \& T. Harris (Eds.), Targeting Regional Economic Development: Routledge.

Deller, S., \& Goetz, S. (2009). Historical description of economic development policy. In S. Goetz, S. Deller \& T. Harris (Eds.), Targeting Regional Economic Development: Routledge.

Due, J. F. (1961). Studies of state-local tax influences on location of industry. National Tax Journal, $163-$ 173. 
Duranton, G., \& Puga, D. (2001). Nursery cities: Urban diversity, process innovation, and the life cycle of products. American Economic Review, 1454-1477.

Eisinger, P. K. (1988). The rise of the entrepreneurial state. State and local economic development policy in the United States. Madison, WI: The University of Wisconsin Press.

Erickson, R., \& Wasylenko, M. (1980). Firm relocation and site selection in suburban municipalities. Journal of Urban Economics, 8, 69-85.

Figueiredo, O., Guimarães, P., \& Woodward, D. (2002). Home-field advantage: location decisions of Portuguese entrepreneurs. Journal of Urban Economics, 52, 341-361.

Giuliano, G. (1989). Research policy and review 27. New directions for understanding transportation and land use. Environment and Planning A, 21(2), 145 - 159

Goetz, S. J., \& Hu, D. (1996). Economic growth and human capital accumulation: Simultaneity and expanded convergence tests. Economics Letters, 51(3), 355-362.

Grant, R. (1996). The ethics of talk: Classroom conversation and democratic politics. The Teachers College Record, 97(3), 470-482.

Grassmueck, G., Goetz, S., \& Shields, M. (2008). Youth out-migration from Pennsylvania: The roles of government fragmentation vs. the Beaten Path Effect. Journal of Regional Analysis and Policy, $38(1), 77-88$.

Greenhalgh, P. (2008). An examination of business occupier relocation decision making: Distinguishing small and large firm behaviour. Journal of Property Research, 25(2), 107-126. doi: $10.1080 / 09599910802605368$

Guimaraes, P., Rolfe, R. J., \& Woodward, D. (1998). Regional incentives and industrial location in Puerto Rico. International Regional Science Review, 21(2), 119-138.

Halstead, J. M., \& Deller, S. (1997). Public infrastructure in economic development and growth: Evidence from rural manufacturers. Journal of the Community Development Society, 28(2), 149169.

Hanushek, E. A., \& Woessmann, L. (2015). The knowledge capital of nations: Education and the economics of growth: MIT Press.

Holguin-Veras, J., Xu, N., Levinson, H., Paaswell, R., McKnight, C., Weiner, R., . . Ozmen-Ertekin, D. (2005). An investigation on the aggregate behavior of firm relocations to New Jersey (19901999) and the underlying market elasticities. Networks and Spatial Economics, 5(3), 293-331. doi: 10.1007/s11067-005-3037-z

Holtz-Eakin, D. (1992). Public-sector capital and the productivity puzzle: National bureau of economic research.

Hong, S. H. (2014). Agglomeration and relocation: Manufacturing plant relocation in Korea. Papers in Regional Science, 93(4), 803-818.

Ibrahim, S. E., Fallah, M. H., \& Reilly, R. R. (2009). Localized sources of knowledge and the effect of knowledge spillovers: An empirical study of inventors in the telecommunications industry. Journal of Economic Geography, 2009, 405-431.

Jenkins, C., Jaynes, A., \& Leicht, K. (2006). Do high technology policies work? An analysis of high technology employment growth in U.S. Metropolitan areas, 1988-1998. Social Science Quarterly, $89(2), 456-481$.

Kalnins, A., \& Chung, W. (2004). Resource-seeking agglomeration: a study of market entry in the lodging industry. Strategic Management Journal, 25(7), 689-699. doi: 10.1002/smj.403

Klassen, K. J., \& Shackelford, D. A. (1998). State and provincial corporate tax planning: income shifting and sales apportionment factor management. Journal of Accounting and Economics, 25(3), 385406.

Knoben, J., \& Oerlemans, L. A. G. (2008). Ties that spatially bind? A relational analysis of the causes of spatial firm mobility. Regional Studies, 42(3), 385-400.

Koo, J. (2005). Agglomeration and spillovers in a simultaneous framework. Annals of Regional Science, 39(1), 35-47. 
Lane, J., Glennon, D., \& McCabe, J. (1989). Measures of local business climate: Alternative approaches. Regional Science Perspectives, 19, 89-106.

Lawson, M. B., \& Angle, H. L. (1998). Upon reflection: commitment, satisfaction, and regret after a corporate relocation. Group \& Organization Management, 23(3), 289-317.

Lee, Y. (2008). Geographic redistribution of US manufacturing and the role of state development policy. Journal of Urban Economics, 64(2), 436-450.

Mack, R. S., \& Schaeffer, P. V. (1993). Nonmetropolitan manufacturing in the United States and product cycle theory: A review of the literature. Journal of Planning Literature, 8(2), 124-139.

McConnell, V. D., \& Schwab, R. M. (1990). The impact of environmental regulation on industry location decisions: The motor vehicle industry. Land Economics, 66(1), 67-81.

National Science Foundation, N. C. f. S. a. E. S. (2014). Business R\&D and Innovation: 2011. Detailed Statistical Tables NSF 15-307. Arlington, VA.

Neumark, D., Zhang, J., \& Wall, B. (2006). Employment Dynamics and Business Relocation: New Evidence from the National Establishment Time Series: University of California-Irvine, Department of Economics.

Newman, R. J., \& Sullivan, D. H. (1988). Econometric analysis of business tax impacts on industrial location: what do we know, and how do we know it? Journal of Urban Economics, 23(2), 215 234.

Nguyen, C., Sano, K., Tran, T., \& Doan, T. (2013). Firm relocation patterns incorporating spatial interactions. The Annals of Regional Science, 50(3), 685-703.

Oakland, W. H. (1978). Local taxes and intraurban industrial location: A survey. Metropolitan financing and growth management policies, 13-30.

Otto, K., \& Dalbert, C. (2010). New challenges for human resource management: readiness to perform a mobile job and its antecedents. The International Journal of Human Resource Management, 21(4), 600-614. doi: 10.1080/09585191003612109

Oukarfi, S., \& Baslé, M. (2009). Public-sector financial incentives for business relocation and effectiveness measures based on company profile and geographic zone. The Annals of Regional Science, 43(2), 509-526.

Ozmen-Ertekin, D., Ozbay, K., \& Holguin-Veras, J. (2007). Role of transportation accessibility in attracting new businesses to New Jersey. Journal of Urban Planning and Development, 133(2), 138-149. doi: 10.1061/(asce)0733-9488(2007)133:2(138)

Pellenbarg, P. H., Wissen, L. J. G. v., \& Dijk, J. v. (2002). Firm relocation: State of the art and research prospects: University of Groningen, Research Institute SOM (Systems, Organisations and Management).

Pennings, E., \& Sleuwaegen, L. (2000). International relocation: firm and industry determinants. Economics Letters, 67, 179-186.

Pitelis, C., \& Pseiridis, A. (2006). A conceptual framework for firm cooperation and clusters, and their impact on productivity. Clusters and globalisation: The development of urban and regional economies, 17-60.

Rink, D. R., \& Swan, J. E. (1979). Product life cycle research: A literature review. Journal of Business Research, 7(3), 219-242.

Ross, D., \& Friedman, R. E. (1990). The emerging third wave: New economic development strategies. Entrepreneurial Economy Review, 90(1), 3-11.

Schaffer, R., Deller, S., \& Marcouiller, D. W. (2004). Community Economics: Linking Theory and Practice, 2nd Edition

(2 ed.): Wiley-Blackwell.

Schmitt, N., Gleason, S. E., Pigozzi, B., \& Marcus, P. M. (1987). Business climate attitudes and company relocation decisions. Journal of Applied Psychology, 72(4), 622-628. doi: 10.1037/00219010.72 .4 .622 
Shaffer, R., Deller, S., \& Marcouiller, D. (2004). Community economics: linking theory and practice: Blackwell Publishing.

Shields, M., Barkley, D., \& Emery, M. (2009). Industry clusters and industry targeting. Targeting Regional Economic Development, 44, 35.

Stam, E. (2007). Why butterflies don't leave: Locational behavior of entrepreneurial firms. Economic Geography, 83(1), 27-50. doi: 10.1111/j.1944-8287.2007.tb00332.x

Strauss-Kahn, V., \& Vives, X. (2009). Why and where do headquarters move? Regional Science and Urban Economics, 39(2), 168-186.

Sugden, R., Wei, P., \& Wilson, J. R. (2006). Clusters, governance and the development of local economies: a framework for case studies. Clusters and globalisation: The development of urban and regional economies, 61-81.

Tatom, J. A. (1991a). Public capital and private sector performance. Federal Reserve Bank of St. Louis Review, 73(May/June 1991).

Tatom, J. A. (1991b). Should government spending on capital goods be raised? Federal Reserve Bank of St. Louis Review, 73(3), 3-15.

van Dijk, J., \& Pellenbarg, P. H. (2000). Firm relocation decisions in The Netherlands: An ordered logit approach. Papers in Regional Science, 79(191-219), 191.

Wasylenko, M. (1980). Evidence of fiscal differentials and intrametropolitan firm relocation. Land Economics, 339-349.

Wasylenko, M. (1981). The location of firms: The role of taxes and fiscal incentives. Urban Government Finance: Emerging Trends, 20, 155-190.

Weterings, A., \& Knoben, J. (2013). Footloose: An analysis of the drivers of firm relocations over different distances. Papers in Regional Science, 92(4), 791-809.

Wilson, R. A., \& Briscoe, G. (2004). The impact of human capital on economic growth: a review. Impact of Education and Training, Third Report on Vocational Training Research in Europe: background report. Luxembourg: Office for Official Publications of the European Communities, Cedefop Reference series, 54.

Wojan, T. R., \& Pulver, G. C. (1995). Location patterns of high growth industries in rural counties. Growth and Change, 26(1), 3-22.

Woodward, D., \& Guimarães, P. (2009). Porter's cluster strategy and industrial targeting. Targeting Regional Economic Development, 68-83.

Woodward, D., \& Rolfe, R. J. (1993). The location of export-oriented foreign direct investment in the Caribbean Basin. Journal of International Business Studies, 121-144.

Zachariadis, M. (2003). R\&D, innovation, and technological progress: A test of the Schumpeterian framework without scale effects. Canadian Journal of Economics, 36(3), 566-586. 
Figure 1: Frequency of Cross-State Mfg Relocations $\left(M_{i j, t}\right)$ Annual $2000-2011$

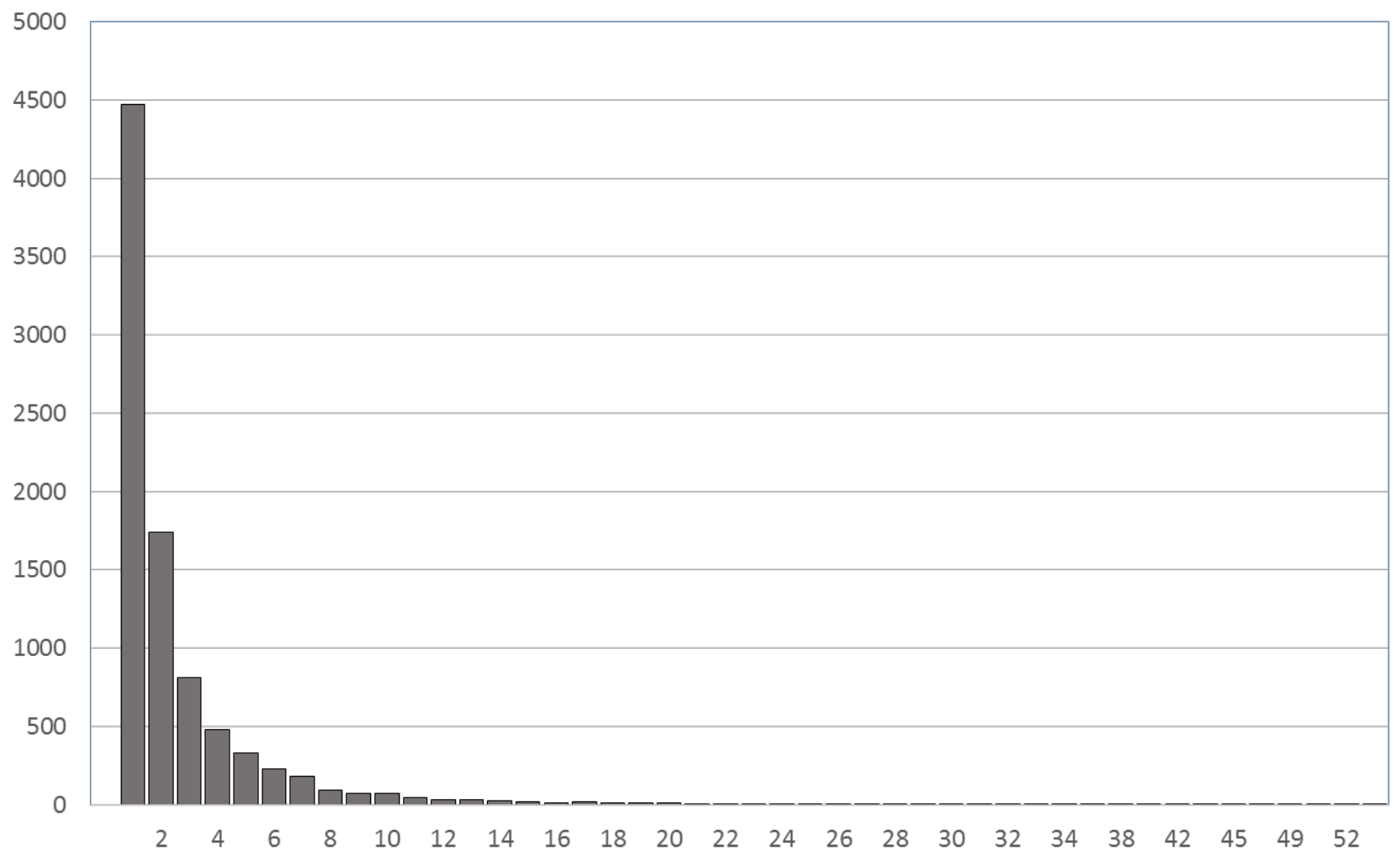

Page | 33 
Table 1: Industry Groupings by Research and Development Activity

\begin{tabular}{|clc|}
\hline NAICS & Industry & Grouping \\
\hline 311 & Food Manufacturing & Low \\
312 & Beverage and Tobacco Product Manufacturing & Low \\
313 & Textile Mills & Low \\
314 & Textile Product Mills & Low \\
315 & Apparel Manufacturing & Low \\
316 & Leather and Allied Product Manufacturing & Low \\
321 & Wood Product Manufacturing & Low \\
322 & Paper Manufacturing & Low \\
323 & Printing and Related Support Activities & Medium \\
324 & Petroleum and Coal Products Manufacturing & Low \\
325 & Chemical Manufacturing & High \\
326 & Plastics and Rubber Products Manufacturing & Low \\
327 & Nonmetallic Mineral Product Manufacturing & Low \\
331 & Primary Metal Manufacturing & Low \\
332 & Fabricated Metal Product Manufacturing & Low \\
333 & Machinery Manufacturing & Medium \\
334 & Computer and Electronic Product Manufacturing & High \\
335 & Electrical Equipment, Appliance, and Component Manufacturing & High \\
336 & Transportation Equipment Manufacturing & High \\
337 & Furniture and Related Product Manufacturing & Medium \\
339 & Miscellaneous Manufacturing & Medium \\
\hline
\end{tabular}


Table 2: Descriptive Data for $\mathrm{M}_{\mathrm{ijt}}$ and $\Delta \mathrm{X}_{\mathrm{ijt}}$

\begin{tabular}{|c|c|c|c|c|}
\hline & Mean & $\begin{array}{c}\text { Standard } \\
\text { Deviation }\end{array}$ & Minimum & Maximum \\
\hline Migration (Count or $\mathrm{M}_{\mathrm{ijt}}$ ) & 2.677 & 3.57 & 1.00 & 62.00 \\
\hline Migration Share & 0.065 & 0.07 & 0.00 & 1.00 \\
\hline State's Share of US Manufacturing GDP & 0.052 & 4.20 & -13.37 & 13.37 \\
\hline Share of State Employment in Manufacturing & -0.072 & 3.99 & -14.24 & 14.87 \\
\hline Compensation per Job in Manufacturing & 0.637 & 12.08 & -41.76 & 40.96 \\
\hline Union Membership Rate & 0.481 & 7.88 & -23.80 & 23.80 \\
\hline Unemployment Rate & -0.033 & 1.68 & -8.80 & 8.50 \\
\hline Share of Population 25+ Years Old with at Least a Bachelor's Degree & 0.398 & 6.24 & -19.00 & 21.90 \\
\hline State Average Electricity Rate & 0.372 & 9.26 & -35.63 & 35.46 \\
\hline Corporate Income Tax per $\$ 1000$ Personal Income & 0.076 & 2.96 & -13.41 & 13.41 \\
\hline Individual Income Tax per $\$ 1000$ Personal Income & 0.477 & 16.76 & -49.06 & 49.06 \\
\hline Property Tax Per $\$ 1000$ of Personal Income & 0.502 & 11.76 & -50.38 & 50.38 \\
\hline Spend on Higher Education per $\$ 1000$ of Personal Income & -0.161 & 7.48 & -23.30 & 23.68 \\
\hline Spend on K12 Education per $\$ 1000$ of Personal Income & 0.133 & 9.60 & -39.52 & 43.64 \\
\hline Welfare Programs per $\$ 1000$ of Personal Income & -0.002 & 12.05 & -45.36 & 46.12 \\
\hline Highways/Roads per $\$ 1000$ of Personal Income & -0.067 & 5.06 & -22.20 & 21.89 \\
\hline Corrections Per $\$ 1000$ of Personal Income & -0.002 & 1.97 & -8.06 & 8.06 \\
\hline Beacon Hill Comp Index & 0.040 & 1.22 & -5.07 & 4.08 \\
\hline Share of State Legislature Held by Democrats & 0.690 & 18.41 & -78.79 & 78.79 \\
\hline Rate of Veto by Governor & 0.108 & 11.32 & -54.26 & 54.26 \\
\hline Neighbors & 0.209 & 0.41 & 0.00 & 1.00 \\
\hline Number of Observations: 8,750 & & & & \\
\hline
\end{tabular}


Table 3: Empirical Modeling Results

\begin{tabular}{|c|c|c|c|c|}
\hline & $\begin{array}{c}\text { All } \\
\text { Manufact } \\
\text { urers }\end{array}$ & $\begin{array}{c}\text { Low R\&D } \\
\text { Manufact } \\
\text { urers }\end{array}$ & $\begin{array}{c}\text { Medium } \\
\text { R\&D } \\
\text { Manufact } \\
\text { uers }\end{array}$ & $\begin{array}{l}\text { High R\&D } \\
\text { Manufact } \\
\text { uring }\end{array}$ \\
\hline \multirow[t]{2}{*}{ State's Share of US Manufacturing GDP } & $0.0113 * *$ & 0.0049 & $0.0223 * *$ & $0.0211 * *$ \\
\hline & $(0.0066)$ & $(0.0093)$ & $(0.0096)$ & $(0.0101)$ \\
\hline \multirow[t]{2}{*}{ Share of State Employment in Manufacturing } & -0.0123 & -0.0024 & -0.0172 & $-0.0242 *$ \\
\hline & $(0.0097)$ & $(0.0129)$ & $(0.0130)$ & $(0.0142)$ \\
\hline \multirow[t]{2}{*}{ Compensation per Job in Manufacturing } & -0.0014 & 0.0058 & -0.0068 & -0.0011 \\
\hline & $(0.0036)$ & $(0.0051)$ & $(0.0046)$ & $(0.0053)$ \\
\hline \multirow[t]{2}{*}{ Union Membership Rate } & $0.0241 * * *$ & $0.0236 * * *$ & $0.0349 * * *$ & $0.0162 * *$ \\
\hline & $(0.0046)$ & $(0.0060)$ & $(0.0065)$ & $(0.0073)$ \\
\hline \multirow[t]{2}{*}{ Unemployment Rate } & 0.0154 & 0.0200 & -0.0001 & 0.0248 \\
\hline & $(0.0190)$ & $(0.0252)$ & $(0.0265)$ & $(0.0280)$ \\
\hline \multirow[t]{2}{*}{ Share of Population 25+ Years Old with at Least a Bachelor's Degree } & -0.0052 & -0.0119 & -0.0021 & 0.0063 \\
\hline & $(0.0089)$ & $(0.0116)$ & $(0.0112)$ & $(0.0135)$ \\
\hline \multirow[t]{2}{*}{ State Average Electricity Rate } & 0.0037 & -0.0006 & 0.0069 & $0.0082 *$ \\
\hline & $(0.0034) *$ & (0.0049) & $(0.0045)$ & $(0.0047)$ \\
\hline \multirow[t]{2}{*}{ Corporate Income Tax per $\$ 1000$ Personal Income } & 0.0202 & 0.0218 & 0.0156 & $0.0376 * *$ \\
\hline & $(0.0107)$ & $(0.0148)$ & $(0.0141)$ & $(0.0154)$ \\
\hline \multirow[t]{2}{*}{ Individual Income Tax per \$1000 Personal Income } & $0.0051 * *$ & $0.0075 * *$ & 0.0048 & 0.0012 \\
\hline & $(0.0023)$ & $(0.0031)$ & $(0.0030)$ & $(0.0034)$ \\
\hline \multirow[t]{2}{*}{ Property Tax Per $\$ 1000$ of Personal Income } & -0.0029 & -0.0031 & 0.0003 & $-0.0089 * *$ \\
\hline & $(0.0030)$ & $(0.0037)$ & (0.0039) & $(0.0045)$ \\
\hline \multirow[t]{2}{*}{ Spend on Higher Education per $\$ 1000$ of Personal Income } & $-0.0103 * *$ & $-0.0240 * * *$ & -0.0018 & -0.0033 \\
\hline & $(0.0051)$ & $(0.0063)$ & $(0.0075)$ & $(0.0076)$ \\
\hline \multirow[t]{2}{*}{ Spend on K12 Education per $\$ 1000$ of Personal Income } & $0.0091 * *$ & 0.0080 & $0.0129 * *$ & 0.0038 \\
\hline & $(0.0041)$ & $(0.0052)$ & $(0.0055)$ & $(0.0064)$ \\
\hline \multirow[t]{2}{*}{ Welfare Programs per $\$ 1000$ of Personal Income } & $-0.0087 * * *$ & -0.0050 & -0.0071 & -0.0017 \\
\hline & $(0.0033)$ & $(0.0045)$ & $(0.0044)$ & $(0.0048)$ \\
\hline \multirow[t]{2}{*}{ Highways/Roads per $\$ 1000$ of Personal Income } & 0.0082 & $0.0180 *$ & 0.0032 & 0.0002 \\
\hline & $(0.0082)$ & $(0.0104)$ & (0.0109) & (0.0118) \\
\hline \multirow[t]{2}{*}{ Corrections Per $\$ 1000$ of Personal Income } & -0.0219 & -0.0329 & -0.0228 & -0.0356 \\
\hline & $(0.0192)$ & $(0.0246)$ & $(0.0249)$ & $(0.0300)$ \\
\hline \multirow[t]{2}{*}{ Beacon Hill Comp Index } & 0.0256 & 0.0458 & 0.0406 & -0.0105 \\
\hline & $(0.0288)$ & $(0.0375)$ & $(0.0399)$ & $(0.0434)$ \\
\hline \multirow[t]{2}{*}{ Share of State Legislature Held by Democrats } & 0.0008 & 0.0006 & 0.0018 & -0.0015 \\
\hline & $(0.0017)$ & $(0.0024)$ & $(0.0023)$ & $(0.0025)$ \\
\hline \multirow[t]{2}{*}{ Rate of Veto by Governor } & 0.0010 & 0.0046 & 0.0005 & -0.0007 \\
\hline & $(0.0024)$ & $(0.0033)$ & $(0.0032)$ & $(0.0035)$ \\
\hline \multirow[t]{2}{*}{ Neighbors } & $1.4308 * * *$ & $1.4736 * * *$ & $1.2230 * * *$ & $1.0212 * * *$ \\
\hline & $(0.0509)$ & $(0.0651)$ & $(0.0695)$ & $(0.0750)$ \\
\hline \multirow[t]{2}{*}{ Intercept } & $-16.7405 * * *$ & $-17.3599 * * *$ & $-17.3583 * * *$ & $-17.8971 * * *$ \\
\hline & $(0.0434)$ & $(0.1495)$ & $(0.2778)$ & $(0.2534)$ \\
\hline Pseudo $\mathrm{R}^{2}$ & 0.0373 & 0.0594 & 0.0479 & 0.0357 \\
\hline
\end{tabular}

Standard error in parentheses.

$* * *$ : Significant at $99.0 \%$

**: Significant at $95.0 \%$

*: $\quad$ Significant at $90.0 \%$ 
Table 4. Marginal Effects at the Means

\begin{tabular}{|c|c|c|c|c|}
\hline & $\begin{array}{c}\text { All } \\
\text { Manufactu } \\
\text { rers }\end{array}$ & $\begin{array}{l}\text { Low R\&D } \\
\text { Manufactu } \\
\text { rers }\end{array}$ & $\begin{array}{c}\text { Medium } \\
\text { R\&D } \\
\text { Manufactu } \\
\text { ers }\end{array}$ & $\begin{array}{l}\text { High R\&D } \\
\text { Manufactu } \\
\text { ring }\end{array}$ \\
\hline State's Share of US Manufacturing GDP & $\begin{array}{l}1.16 \mathrm{E}-099^{*} \\
(0.0000)\end{array}$ & $\begin{array}{r}4 \mathrm{E}-10 \\
(0.0000)\end{array}$ & $\begin{array}{l}1.37 \mathrm{E}-09 * * \\
(0.0000)\end{array}$ & $\begin{array}{l}0.005417 \text { ** } \\
(0.0026)\end{array}$ \\
\hline Share of State Employment in Manufacturing & $\begin{array}{r}-1.26 \mathrm{E}-09 \\
(0.0000)\end{array}$ & $\begin{array}{r}-2 \mathrm{E}-10 \\
(0.0000)\end{array}$ & $\begin{array}{r}-1.06 \mathrm{E}-09 \\
(0.0000)\end{array}$ & $\begin{array}{c}-0.006224 * \\
(0.0037)\end{array}$ \\
\hline Compensation per Job in Manufacturing & $\begin{array}{l}-1.5 \mathrm{E}-10 \\
(0.0000)\end{array}$ & $\begin{array}{r}5 E-10 \\
(0.0000)\end{array}$ & $\begin{array}{l}-4.2 \mathrm{E}-10 \\
(0.0000)\end{array}$ & $\begin{array}{r}-0.000272 \\
(0.0014)\end{array}$ \\
\hline Union Membership Rate & $\begin{array}{l}2.47 \mathrm{E}-09 * * * \\
(0.0000)\end{array}$ & $\begin{array}{r}2 \mathrm{E}-09 \text { * } \\
(0.0000)\end{array}$ & $\begin{array}{l}2.14 \mathrm{E}-09 * * * \\
(0.0000)\end{array}$ & $\begin{array}{l}0.004167^{* *} \\
(0.0019)\end{array}$ \\
\hline Unemployment Rate & $\begin{array}{r}1.58 \mathrm{E}-09 \\
(0.0000)\end{array}$ & $\begin{array}{r}1.7 \mathrm{E}-09 \\
(0.0000)\end{array}$ & $\begin{array}{r}-1 \mathrm{E}-11 \\
(0.0000)\end{array}$ & $\begin{array}{r}0.006368 \\
(0.0072)\end{array}$ \\
\hline Share of Population $25+$ Years Old with at Least a Bachelor's Degree & $\begin{array}{l}-5.4 \mathrm{E}-10 \\
(0.0000)\end{array}$ & $\begin{array}{r}-1 \mathrm{E}-09 \\
(0.0000)\end{array}$ & $\begin{array}{l}-1.3 \mathrm{E}-10 \\
(0.0000)\end{array}$ & $\begin{array}{r}0.001608 \\
(0.0035)\end{array}$ \\
\hline State Average Electricity Rate & $\begin{array}{r}3.8 \mathrm{E}-10 \\
(0.0000)\end{array}$ & $\begin{array}{r}-1 \mathrm{E}-10 \\
(0.0000)\end{array}$ & $\begin{array}{r}4.3 \mathrm{E}-10 \\
(0.0000)\end{array}$ & $\begin{array}{c}0.002098 * \\
(0.0012)\end{array}$ \\
\hline Corporate Income Tax per $\$ 1000$ Personal Income & $\begin{array}{c}2.08 \mathrm{E}-09 * \\
(0.0000)\end{array}$ & $\begin{array}{r}1.8 \mathrm{E}-09 \\
(0.0000)\end{array}$ & $\begin{array}{r}9.6 \mathrm{E}-10 \\
(0.0000)\end{array}$ & $\begin{array}{c}0.009668 \text { ** } \\
(0.0040)\end{array}$ \\
\hline Individual Income Tax per $\$ 1000$ Personal Income & $\begin{array}{l}5.3 \mathrm{E}-10 * * \\
(0.0000)\end{array}$ & $\begin{array}{r}6 \mathrm{E}-10 \\
(0.0000)\end{array}$ & $\begin{array}{r}2.9 \mathrm{E}-10 \\
(0.0000)\end{array}$ & $\begin{array}{r}0.000318 \\
(0.0009)\end{array}$ \\
\hline Property Tax Per $\$ 1000$ of Personal Income & $\begin{array}{r}-3 E-10 \\
(0.0000)\end{array}$ & $\begin{array}{r}-3 E-10 \\
(0.0000)\end{array}$ & $\begin{array}{r}2 \mathrm{E}-11 \\
(0.0000)\end{array}$ & $\begin{array}{c}-0.002295 * * \\
(0.0012)\end{array}$ \\
\hline Spend on Higher Education per $\$ 1000$ of Personal Income & $\begin{array}{c}-1.06 \mathrm{E}-09 * * \\
(0.0000)\end{array}$ & $\begin{array}{l}-2 \mathrm{E}-09 * \\
(0.0000)\end{array}$ & $\begin{array}{l}-1.1 \mathrm{E}-10 \\
(0.0000)\end{array}$ & $\begin{array}{r}-0.000842 \\
(0.0020)\end{array}$ \\
\hline Spend on K12 Education per $\$ 1000$ of Personal Income & $\begin{array}{l}9.4 \mathrm{E}-10 * * \\
(0.0000)\end{array}$ & $\begin{array}{r}7 \mathrm{E}-10 \\
(0.0000)\end{array}$ & $\begin{array}{l}7.9 \mathrm{E}-10 * * \\
(0.0000)\end{array}$ & $\begin{array}{r}0.000975 \\
(0.0017)\end{array}$ \\
\hline Welfare Programs per $\$ 1000$ of Personal Income & $\begin{array}{l}-9 \mathrm{E}-10 * * * \\
(0.0000)\end{array}$ & $\begin{array}{r}-4 \mathrm{E}-10 \\
(0.0000)\end{array}$ & $\begin{array}{l}-4.4 \mathrm{E}-10 \\
(0.0000)\end{array}$ & $\begin{array}{r}-0.000434 \\
(0.0012)\end{array}$ \\
\hline Highways/Roads per $\$ 1000$ of Personal Income & $\begin{array}{r}8.4 \mathrm{E}-10 \\
(0.0000)\end{array}$ & $\begin{array}{r}1.5 \mathrm{E}-09 \\
(0.0000)\end{array}$ & $\begin{array}{r}1.9 \mathrm{E}-10 \\
(0.0000)\end{array}$ & $\begin{array}{r}0.000061 \\
(0.0030)\end{array}$ \\
\hline Corrections Per $\$ 1000$ of Personal Income & $\begin{array}{r}-2.25 \mathrm{E}-09 \\
(0.0000)\end{array}$ & $\begin{array}{l}-2.8 \mathrm{E}-09 \\
(0.0000)\end{array}$ & $\begin{array}{l}-1.4 \mathrm{E}-09 \\
(0.0000)\end{array}$ & $\begin{array}{l}-0.00917 \\
(0.0077)\end{array}$ \\
\hline Beacon Hill Comp Index & $\begin{array}{r}2.64 \mathrm{E}-09 \\
(0.0000)\end{array}$ & $\begin{array}{r}3.8 \mathrm{E}-09 \\
(0.0000)\end{array}$ & $\begin{array}{r}2.49 \mathrm{E}-09 \\
(0.0000)\end{array}$ & $\begin{array}{r}-0.002697 \\
(0.0112)\end{array}$ \\
\hline Share of State Legislature Held by Democrats & $\begin{array}{r}8 \mathrm{E}-11 \\
(0.0000)\end{array}$ & $\begin{array}{r}1 \mathrm{E}-10 \\
(0.0000)\end{array}$ & $\begin{array}{r}1.1 \mathrm{E}-10 \\
(0.0000)\end{array}$ & $\begin{array}{r}-0.000395 \\
(0.0007)\end{array}$ \\
\hline Rate of Veto by Governor & $\begin{array}{r}1 \mathrm{E}-10 \\
(0.0000) \\
\end{array}$ & $\begin{array}{r}4 \mathrm{E}-10 \\
(0.0000) \\
\end{array}$ & $\begin{array}{r}3 E-11 \\
(0.0000) \\
\end{array}$ & $\begin{array}{r}-0.000188 \\
(0.0009)\end{array}$ \\
\hline
\end{tabular}

Standard error in parentheses.

***: Significant at $99.0 \%$

**: Significant at $95.0 \%$

*: $\quad$ Significant at $90.0 \%$ 